\title{
Antioxidant defence in UV-irradiated tobacco leaves is centred on hydrogen-peroxide neutralization
}

\author{
Petra Majer ${ }^{\text {a, } 1}$, Gyula Czégény ${ }^{\text {a, b }}$, Györgyi Sándor a, Philip J. Dix ${ }^{c}$, Éva Hideg b, * \\ ${ }^{a}$ Institute of Plant Biology, Biological Research Centre, Hungarian Academy of Sciences, Szeged, Hungary \\ ${ }^{\mathrm{b}}$ Department of Plant Biology, Institute of Biology, University of Pécs, Pécs, Hungary \\ ${ }^{\mathrm{c}}$ Biology Department, National University of Ireland Maynooth, Maynooth, Co. Kildare, Ireland
}

\section{A R T I C L E I N F O}

Article history:

Received 8 May 2014

Accepted 17 June 2014

Available online 25 June 2014

\section{Keywords:}

Antioxidant

Peroxidase

Photosynthesis

Reactive oxygen species

Hydrogen peroxide

Tobacco

UV treatment

\begin{abstract}
A B S T R A C T
Greenhouse grown tobacco (Nicotiana tabacum L. cv. Petit Havana) plants were exposed to supplemental UV centred at $318 \mathrm{~nm}$ and corresponding to $13.6 \mathrm{~kJ} \mathrm{~m}^{-2} \mathrm{~d}^{-1}$ biologically effective UV-B $(280-315 \mathrm{~nm})$ radiation. After 6 days this treatment decreased photosynthesis by $30 \%$. Leaves responded by a large increase in UV-absorbing pigment content and antioxidant capacities. UV-stimulated defence against ROS was strongest in chloroplasts, since activities of plastid enzymes FeSOD and APX had larger relative increases than other, non-plastid specific SODs or peroxidases. In addition, non-enzymatic defence against hydroxyl radicals was doubled in UV treated leaves as compared to controls. In UV treated leaves, the extent of activation of ROS neutralizing capacities followed a peroxidases $>$ hydroxyl-radical neutralization $>$ SOD order. These results suggest that highly effective hydrogen peroxide neutralization is the focal point of surviving UV-inducible oxidative stress and argue against a direct signalling role of hydrogen peroxide in maintaining adaptation to UV, at least in laboratory experiments.
\end{abstract}

() 2014 Elsevier Masson SAS. All rights reserved.

\section{Introduction}

Recent research shows that at mid-latitudes of the Northern hemisphere ambient solar ultraviolet $(280-400 \mathrm{~nm})$ radiation is rather a developmental signal than a direct stressor for plants (Brosché and Strid, 2003; Jenkins, 2009; Ballaré et al., 2011; Hideg et al., 2013). However, the same UV wavelengths may cause reactive oxygen species (ROS) mediated oxidative stress when applied in controlled environments, such as growth cabinets or greenhouses where PAR to UV ratios are lower than in nature. Whether these treatments result in severe cell damage or acclimative responses depends on several factors including growth conditions preceding the UV treatment as well as doses and wavelength distribution of

Abbreviations: ABTS, 2,2'-azino-bis(3-ethylbenzothiazoline-6-sulphonic acid; APX, ascorbate peroxidase enzyme, EC 1.11.1.11; FRAP, ferric reducing antioxidant power; Fv/Fm, maximum PS II quantum yield; PAR, photosynthetically active radiation; PS, Photosystem; POD, peroxidase enzymes, EC 1.11.1.x; PPFD, photosynthetic photon flux density; SOD, superoxide dismutase enzymes, EC 1.15.1.1; UV, ultraviolet, $280-400 \mathrm{~nm}$; Y(II), light acclimated effective PS II quantum yield.

* Corresponding author. University of Pécs, Ifjúság u. 6, H-7624 Pécs, Hungary. Tel.: +3672 503600.

E-mail address: ehideg@gamma.ttk.pte.hu (É. Hideg).

1 Permanent address: Corvinus University of Budapest, Department of Viticulture, H-1118 Budapest, Villányi út 29-43, Hungary. the applied artificial UV source. Metabolic responses include an increase in epidermal UV absorbing pigment content and in cellular antioxidants (Carletti et al., 2003; Yannarelli et al., 2006; Fini et al., 2011; Majer and Hideg, 2012a, 2012b). When applied at very high (20-40-times of ambient) intensities, $312 \mathrm{~nm}$ centred UV-B generated a variety of reactive oxygen species (ROS) in leaves including superoxide and hydroxyl radicals at concentrations detectable by EPR spin trapping (Hideg and Vass, 1996). UV irradiation of leaf segments pre-loaded with either superoxide radical or singlet oxygen selective fluorescent ROS probes showed that when UV was applied alone, without PAR, higher energy UV-B and lower energy UV-A generated different ROS (Barta et al., 2004). Since these methods are not sensitive enough to quantify ROS in leaf tissues exposed to lower, near-ambient UV intensities, the presence of ROS in such experiments is only assumed from increased antioxidant activities (Carletti et al., 2003; Fini et al., 2011; Majer and Hideg, 2012a). The aim of the present study was to explore acclimative responses of tobacco leaves to supplementary UV radiation in a controlled environment experiment, in terms of ROS specific antioxidants. Daily UV-B doses applied in our experiment were approximately 1.8-times higher than ambient doses in the Northern hemisphere (latitude $46^{\circ}$ ) in summer (Bassman et al., 2001) and were applied in combination with lower than ambient PAR, which aggravates the effect of UV. Consequently, 
our results cannot be directly related to naturally occurring UV but may help to further elucidate plant responses to these conditions.

\section{Methods}

\subsection{Plant growing and UV treatment conditions}

Tobacco (Nicotiana tabacum L. cv. Petit Havana SR1) plants were grown in growth chambers (Fitoclima D1200, Aralab, Portugal) at $25 / 20{ }^{\circ} \mathrm{C}$, at $16 \mathrm{~h}$ daily irradiation with ca. $150 \mu \mathrm{mol} \mathrm{m}{ }^{-2} \mathrm{~s}^{-1}$ photosynthetic photon flux density (PPFD). Four-week old plants were treated for 6 days afterwards, in two groups each containing three plants. The first group (UV plants) was exposed to low dose supplemental UV radiation from Q-Panel UVB-313EL tubes (Q-Lab Ltd., Bolton, UK) through a cellulose diacetate filter (Courtaulds Chemicals, Derby, UK) and the second group (control plants) were kept under PAR only. The applied UV was centred at $318 \mathrm{~nm}$ (Majer and Hideg, 2012a) and corresponded to $15.6 \mathrm{~kJ} \mathrm{~m}^{-2} \mathrm{~d}^{-1}$ global $(280-400 \mathrm{~nm})$ or $13.6 \mathrm{~kJ} \mathrm{~m}^{-2} \mathrm{~d}^{-1}$ UV-B (280-315 nm) biologically effective dose as calculated using the Biological Spectral Weighting Function developed by Ref. Flint and Caldwell (2003). PAR was $50-55 \mu \mathrm{mol} \mathrm{m}{ }^{-2} \mathrm{~s}^{-1}$ PPFD for both UV and control plants. At the end of the 6-day treatment, the last fully-developed leaf (at the 3 rd-4th node) was chosen from each plant for analysis. Photosynthesis and electron transport (Section 2.2) were measured on intact plants, and the same leaves were sampled for pigment and antioxidant analyses (2.3-2.4). The whole experiment was repeated with newly grown plants using the same growth and treatment conditions.

\subsection{Photosynthesis and variable chlorophyll fluorescence measurements}

Photosynthesis was characterized by $\mathrm{CO}_{2}$ uptake $\left(\mu \mathrm{mol} \mathrm{CO} \mathrm{m}^{-2} \mathrm{~s}^{-1}\right)$ measured on intact leaves at $200 \mu \mathrm{mol}$ photons $\mathrm{m}^{-2} \mathrm{~s}^{-1}$ PPFD using a LI-6400 Portable Photosynthesis System (LICOR Environmental, Lincoln, Nebraska USA). Following this, plants were kept in darkness for 30 min before chlorophyll fluorescence measurements were made using the MAXI-version of the ImagingPAM (Heinz Walz GmbH, Effeltrich, Germany). Maximal (Fv/Fm) and light acclimated effective PS II quantum yields (Y(II)) were determined according to Genty et al. (1989). Light acclimated Y(II) was measured at the end of a $5 \mathrm{~min}$ exposure to $55 \mu \mathrm{mol} \mathrm{m}^{-2} \mathrm{~s}^{-1}$ actinic light.

\subsection{Pigment analysis}

Two $1 \mathrm{~cm}$ diameter discs were cut from each leaf and soaked in either $80 \%$ acetone or acidified methanol at $4{ }^{\circ} \mathrm{C}$ in darkness for $24 \mathrm{~h}$. Following this, leaf discs were ground in the same medium and centrifuged $\left(3,000 \times \mathrm{g}, 5 \mathrm{~min}, 4^{\circ} \mathrm{C}\right)$. Supernatants made from acetone extracts were used for photometric determination of chlorophyll and carotenoid contents, based on absorbances measured at 664.6, 646.6 and $440.5 \mathrm{~nm}$ (Yang et al., 1998). Supernatants of acidified methanol extracts were used for assessing total UV-B absorption (the area under the absorption curve integrated between 280 and $315 \mathrm{~nm}$ ). Absorption measurements were carried out using a Shimadzu UV1601 photometer.

\subsection{Antioxidant measurements}

Twelve leaf discs (diameter $=1 \mathrm{~cm}$ ) were weighed and ground first in liquid nitrogen then in $0.8 \mathrm{~mL}$ Na-phosphate buffer ( $50 \mathrm{mM}$, $\mathrm{pH}$ 7.0, $1 \mathrm{mM}$ EDTA). When processing leaf discs for ascorbate peroxidase activity measurements, the isolating buffer contained
$5 \mathrm{mM}$ ascorbate in addition to the above components. Cell debris was removed by low speed centrifugation $\left(3,000 \times \mathrm{g}, 5 \mathrm{~min}, 4^{\circ} \mathrm{C}\right)$, then supernatants were re-centrifuged at higher speed $(30,000 \times \mathrm{g}$, $25 \mathrm{~min}, 4^{\circ} \mathrm{C}$ ). Protein contents of the extracts were determined using the standard Bradford assay (Bradford, 1976) and samples were stored at $-80^{\circ} \mathrm{C}$ until performing antioxidant measurements.

\subsubsection{Photometric antioxidant capacity measurements}

Hydroxyl radical $(\cdot \mathrm{OH})$ scavenging was determined based on the ability of the leaf extracts to inhibit the formation of the $\cdot \mathrm{OH}-$ mediated oxidation of low fluorescence terephthalate acid $(1,4-$ benzenedicarboxylic acid, TPA) to high fluorescence 2hydroxyterephthalate (HTPA). HTPA fluorescence was measured using a Quanta Master QM-1 spectrofluorometer (Photon Technology Inc., Birmingham, New Jersey, USA), and $\cdot \mathrm{OH}$ antioxidant capacities of leaf extracts were characterized by their halfinhibitory concentration on HTPA formation as described earlier (Stoyanova et al., 2011). Ethanol was used for calibration and $\cdot \mathrm{OH}$ antioxidant capacities of leaf extracts were given as $\mu \mathrm{M}$ ethanol equivalent $\mathrm{g}^{-1}$ leaf fresh weight.

Peroxidase (EC 1.11.1.7) activity was tested using the ABTS method (Childs and Bardsley, 1975). The reagent solution contained $10 \%$ ABTS (2,2'-azino-bis(3-ethylbenzothiazoline-6-sulphonic acid)) in $50 \mathrm{mM}$ citrate buffer ( $\mathrm{pH} 5.0$ ) and $360 \mu \mathrm{M} \mathrm{H}_{2} \mathrm{O}_{2}$. The POD activity of the samples was tested against the activity of standard horseradish peroxidase (Sigma) and was expressed as unit POD $\mathrm{mg}^{-1}$ protein.

SOD activity was measured as inhibition of superoxide-induced reduction of nitro blue tetrazolium (NBT) to formazan (Giannopolitis and Ries, 1977) as described earlier (Majer et al., 2010). The reaction mixture contained $0.015 \mathrm{U}$ xanthine-oxidase in $50 \mathrm{mM}$ Na-phosphate buffer (pH 7.2) with $0.3 \mathrm{mM}$ EDTA, $0.2 \mathrm{mM}$ xanthine, and formazan production was measured as absorption change at $560 \mathrm{~nm}$. Results were expressed as unit SOD $\mathrm{mg}^{-1}$ protein.

FRAP (ferric reducing antioxidant power) assay was carried out according to a modification of the original medicinal biochemical assay (Benzie and Strain, 1996) as detailed in Majer and Hideg (2012b). Ascorbic acid (AsA) was used for calibration and FRAP values were expressed as $\mu \mathrm{mol}$ AsA equivalents $\mathrm{g}^{-1}$ leaf fresh weight.

\subsubsection{SOD and APX activity measurements using native PAGE}

To determine enzyme activities, samples were first separated on SDS free native 12\% PAGE. Gels for APX activity contained $4 \mathrm{mM}$ ascorbate. After separation, gels were rinsed either in distilled water (SOD gels) or in a $50 \mathrm{mM}$ Na-phosphate buffer ( $\mathrm{pH} 7.0$ ) containing $4 \mathrm{mM}$ ascorbate (APX gels). This was followed by staining procedures which were carried out at room temperature.

SOD activities were determined as described by Song et al. (2007). First gels were incubated in darkness for $30 \mathrm{~min}$ in a $50 \mathrm{mM}$ Na-phosphate buffer ( $\mathrm{pH} 7.8$ ) containing $1 \mathrm{mM}$ EDTA, $0.05 \mathrm{mM}$ riboflavin, $0.1 \mathrm{mM} \mathrm{NBT}$ and $0.3 \% \mathrm{~N}, \mathrm{~N}, \mathrm{~N}^{\prime \prime}, \mathrm{N}^{\prime \prime}$-tetramethylethylenediamine (TEMED). Following this, gels were rinsed in water and illuminated for 15 min to make the colourless bands with SOD activities in the purple-stained gel visible. To separate various SOD isoforms, either $2 \mathrm{mM} \mathrm{KCN}$ (a Cu/Zn-SOD inhibitor) or $2 \mathrm{mM}$ $\mathrm{H}_{2} \mathrm{O}_{2}$ (inhibitor of FeSOD and $\mathrm{Cu} / \mathrm{Zn}-\mathrm{SOD}$ ) was added to the staining mixture.

APX activity was determined according to Mittler and Zilinkas (1993). Gels were first incubated in a Na-phosphate buffer ( $\mathrm{pH}$ 7.8) containing $8 \mathrm{mM}$ ascorbate and $4 \mathrm{mM} \mathrm{H}_{2} \mathrm{O}_{2}$, then rinsed with buffer and stained with a mixture containing $2.45 \mathrm{mM}$ nitro blue tetrazolium (NBT) and $28 \mathrm{mM}$ TEMED in $50 \mathrm{mM}$ Na-phosphate buffer ( $\mathrm{pH}$ 7.8). APX activity was visualized as colourless bands on 
the greyish-blue gel, where the colouration was caused by TEMEDformazan, formed in a reaction between TEMED-NBT and ascorbate.

Gels were analyzed with ImageJ software (Schneider et al., 2012) to quantify relative activities. Changes in SOD and APX activities brought about by the preceding UV treatment of leaves were determined as percentages of control leaf values.

\subsection{Statistics}

With the exception of native PAGE based enzyme activity measurements, all parameters were measured six-times, using six different leaves representing two biological repetitions and 3-3 parallels of UV or control samples in each repetition. Samples were pooled for SOD and APX activities in gels and these were measured twice, representing the two biological repetitions. Student's $t$-test was used to compare means and to calculate $P$-values, and differences were considered significant at $P<0.05$.

\section{Results and discussion}

\subsection{Photosynthetic responses to supplemental UV}

Fig. 1 illustrates changes induced by the 6-day supplemental UV treatment in tobacco leaves. Photosynthesis measured as $\mathrm{CO}_{2}$ uptake at $200 \mu \mathrm{mol}$ photons $\mathrm{m}^{-2} \mathrm{~s}^{-1}$ was $30 \%$ lower than in controls (Fig. 1A). Both potential (maximum, Fv/Fm) quantum yields and effective (Y(II)) PSII quantum yields were lower in UV treated leaves than in controls. Y(II) was only $18 \%$ lower when measured at $55 \mu \mathrm{mol}$ photons $\mathrm{m}^{-2} \mathrm{~s}^{-1}$ (which was the PAR applied during the UV treatment) and the difference between UV treated and control leaves was even smaller, 8-12\%, when measured at $200 \mu \mathrm{mol}$ photons $\mathrm{m}^{-2} \mathrm{~s}^{-1}$ (data not shown). High doses of UV-B were shown to have a direct effect on stomata (Nogues et al., 1999), in addition to changes in mesophyll photosynthesis including a decrease in both the amount and the activity of Rubisco (Strid et al., 1990; Allen et al., 1997). Supplemental UV did not result in a significant change in stomata conductance and caused a larger decrease in photosynthetic $\mathrm{CO}_{2}$ uptake than in photochemical yield, suggesting that a partial inactivation of dark reactions contributes to the lower photosynthesis in UV treated leaves. This implies that the applied supplemental UV resulted in stress, although a major part of photosynthesis was maintained during the treatment allowing acclimatory responses to occur.

\subsection{Pigment responses to supplemental UV}

The taxing nature of supplemental UV is also shown by a significant, 12 and 34\% loss of leaf chlorophyll and carotenoid contents respectively, by the end of the 6-day treatment (Fig. 1A). On the other hand, a large, $80 \%$ increase in UV-absorbing pigment content supports the occurrence of acclimatory processes. Whole leaf extracts contain both epidermal UV screening pigments and various other UV absorbing flavonoids with primarily antioxidant functions (Caldwell et al., 1983; Middleton and Teramura, 1993; Zhang and Björn, 2009). An increase in UV absorbing pigment content is a common response when UV is applied to greenhouse grown plants (Liu et al., 1995; Carletti et al., 2003; Garcia Macias et al., 2007). Several plant metabolites, for example various flavonoids feature both UV absorbing and antioxidant characteristics (Agati and Tattini, 2010; Majer et al., 2014). In our experiment, the observed strong increase in the UV absorbing capacity of leaf extracts suggested an increase in non-enzymatic antioxidants, which were assessed as total antioxidant capacity.

\subsection{Antioxidant responses to supplemental UV}

Extracts from UV treated leaves had more than twice (236\%) the total antioxidant capacity (measured as FRAP) compared to untreated leaves (Fig. 1B). In addition to this total capacity, specific ROS neutralizing capacities were also measured. The applied UV treatment had no significant effect on either total superoxide scavenging capacity (data not shown) or $\mathrm{Cu} / \mathrm{Zn}-\mathrm{SOD}$, but increased the activity of chloroplast-located Fe-SOD by 65\% (Fig. 1B). Chloroplastic $\mathrm{Cu} / \mathrm{Zn}-\mathrm{SOD}$ in tobacco is only present in detectable amounts in immature leaves, and the abundant isoform in chloroplasts is Fe-SOD which is present at a relatively constant level in photosynthetic tissues of various ages (Van Camp et al., 1997). The
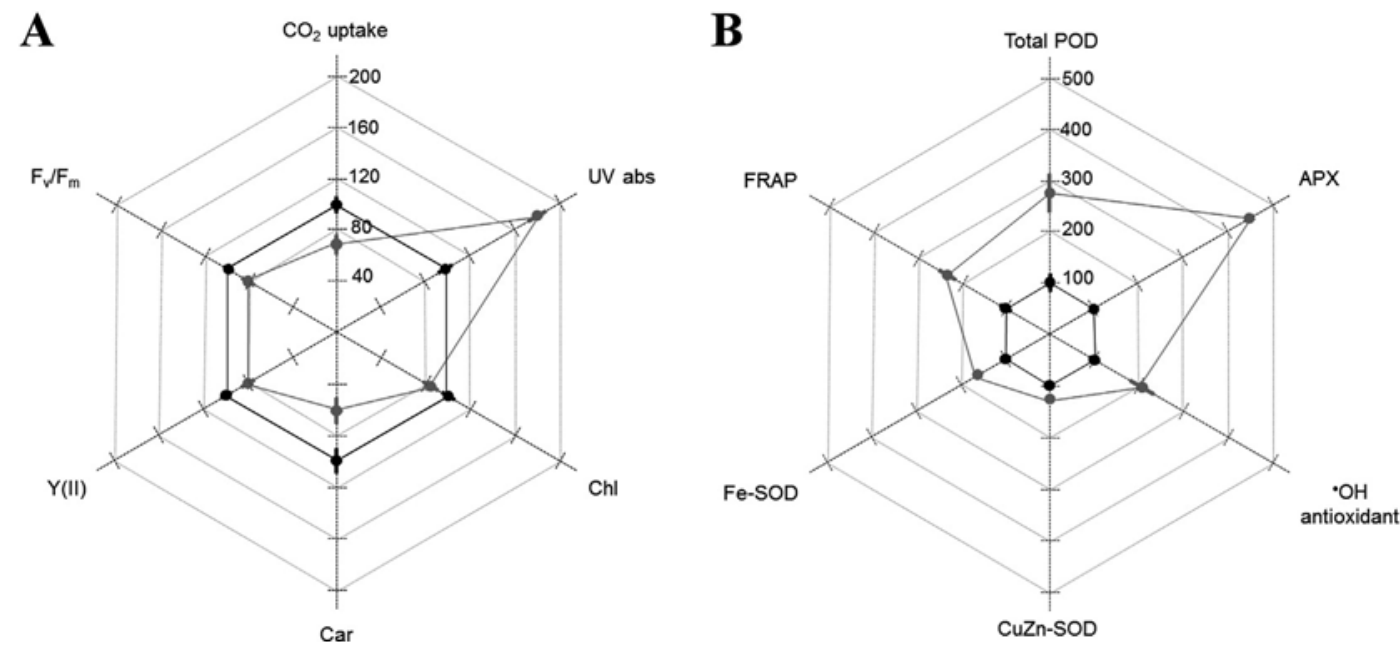

Fig. 1. Tobacco leaf responses to 6-day supplementary UV treatment. Black and red symbols correspond to untreated (PAR only) and UV-B treated (PAR + UV-B) leaves, respectively. Changes in (A) leaf photosynthesis, photochemical quantum yields, pigment content and (B) antioxidant capacities are shown as \% of corresponding values in untreated leaves. Data points represent averages and error bars correspond to standard deviations ( $n=3$ for Fe-SOD, Cu/Zn-SOD and APX, $n=6$ for all other samples). 100\% values are: Photosynthesis, $6.73 \pm 1.14 \mu \mathrm{mol} \mathrm{CO} 2 \mathrm{~m}^{-2} \mathrm{~s}^{-1}$ uptake; Maximum PSII quantum yield Fv/Fm, $0.783 \pm 0.005$; Effective PSII quantum yield at $55 \mu \mathrm{mol}$ photons $\mathrm{m}^{-2} \mathrm{~s}^{-1} \mathrm{Y}(\mathrm{II}), 0.607 \pm 0.022$; Total carotenoid content (Car) $1.834+0.701 \mu \mathrm{g} \mathrm{g}^{-1} \mathrm{FW}$; Total chlorophyll content (Chl) $23.978+2.916 \mu \mathrm{g} \mathrm{g}^{-1} \mathrm{FW}$; Total UV-B absorbing pigment content (UV abs) $35.435 \pm 52.116$ OD nm;

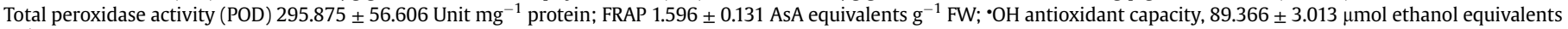
$\mathrm{g}^{-1} \mathrm{FW}$. Fe-SOD, Cu/Zn-SOD and APX activity data were evaluated using native gel images and activities were not quantified as enzyme units. 
observed large increase in Fe-SOD in UV-treated leaves suggests a plastid response. Our Fe-SOD activity data are in agreement with the result of Kliebenstein et al. (1998) who reported increased gene expression and protein levels of Fe-SOD in Arabidopsis in response to $15 \mathrm{~kJ} \mathrm{~m}^{-2} \mathrm{~d}^{-1} \mathrm{UV}-\mathrm{B}$, a condition very similar to the one applied in our experiment. Increased superoxide neutralization leads to higher $\mathrm{H}_{2} \mathrm{O}_{2}$ concentrations; thus a successful acclimation to UV also requires effective $\mathrm{H}_{2} \mathrm{O}_{2}$ antioxidants. In our experiment, both total peroxidase and plastid APX activities increased to much larger extents (by 170 and 340\%, respectively) than Fe-SOD (Fig. 1B). These results differ from those found by Fini et al. (2011) in wild privet (Ligustrum vulgare) leaves exposed to higher supplemental UV doses $\left(803 \mathrm{~kJ} \mathrm{~m}^{-2} \mathrm{UV}-\mathrm{A}+38.8 \mathrm{~kJ} \mathrm{~m}^{-2} \mathrm{UV}-\mathrm{B}\right)$. In their experiment both SOD and APX increased by approximately $30-40 \%$ by the 8 th day of treatment but decreased afterwards to or even below activities measured in control leaves (Fini et al., 2011). The authors attributed the observed steep decline in APX activity to an acclimative response, assuming that higher plastid $\mathrm{H}_{2} \mathrm{O}_{2}$ concentrations prompted signalling to increase flavonoid biosynthesis (Fini et al. 2011). In another study, Yannarelli et al. (2006) found that sunflower plants acclimatized to 15 or $30 \mathrm{~kJ} \mathrm{~m}^{-2}$ biologically effective UV-B through the induction of various peroxidases, but not of APX which remained unaltered. Although differences in UV sources, UV dose and plant species make direct comparisons with these studies difficult, our data clearly contradict observations of decreased or unaltered APX activities in response to UV-B. In our experiment, the marked increase in peroxidase defence, especially in APX, suggests that increased $\mathrm{H}_{2} \mathrm{O}_{2}$ concentrations in UV exposed leaves are hazardous rather than beneficial. It is important to note that although tobacco leaves reportedly contain catalase forms which also possess peroxidatic activity (Havir and McHale, 1987) the assay applied in our study may underestimate total $\mathrm{H}_{2} \mathrm{O}_{2}$ neutralizing activities due to its insensitivity to monofunctional forms. The importance of efficient defence against $\mathrm{H}_{2} \mathrm{O}_{2}$ may be explained by the possibility of UV-B inducible photo-cleavage of $\mathrm{H}_{2} \mathrm{O}_{2}$ yielding highly oxidizing hydroxyl radicals (Czégény et al., 2014). This is supported by the observation that protection against $\cdot \mathrm{OH}$ was doubled in UV-B exposed leaves (Fig. 1B). In addition, ferric reducing capacities were also enhanced protecting against an UV-B independent, Fenton-type $\mathrm{H}_{2} \mathrm{O}_{2} \rightarrow \cdot \mathrm{OH}$ reaction, although to a smaller extent than that of peroxidase defence (Fig. 1B).

\section{Conclusions}

In leaves $\mathrm{H}_{2} \mathrm{O}_{2}$ is part of the complex signalling network that may induce acclimatory defence responses as well as cell death (Neill et al., 2002; Apel and Hirt, 2004). ROS concentrations during acclimative responses should be optimized to fulfil signalling roles while avoiding oxidative damage. It was recently suggested that not only concentrations per se, but ratios of different ROS, determine the activation of the defence network or programmed cell death. According to Sabater and Martin (2013) a high $\left({ }^{1} \mathrm{O}_{2}+\mathrm{O}_{2}^{-} \cdot\right) / \mathrm{H}_{2} \mathrm{O}_{2}$ concentration ratio could trigger a transition from defence to senescence responses. It follows from this model that when relatively low PAR results in lower photooxidative pressure which is less likely to lead to chloroplastic ${ }^{1} \mathrm{O}_{2}$ production it takes less $\mathrm{H}_{2} \mathrm{O}_{2}$ to keep $\left({ }^{1} \mathrm{O}_{2}+\mathrm{O}_{2}^{-} \cdot\right) / \mathrm{H}_{2} \mathrm{O}_{2}$ low. Accordingly, supplemental UV-B treatment in our experiment resulted in augmented $\mathrm{H}_{2} \mathrm{O}_{2}$ neutralization allowing high chloroplastic peroxidase activity to protect from possible UV-B induced hydroxyl radical production (Czégény et al., 2014) without risking an increase in $\left({ }^{1} \mathrm{O}_{2}+\mathrm{O}_{2}^{-} \cdot\right) /$ $\mathrm{H}_{2} \mathrm{O}_{2}$. This situation is different from experiments where high intensity PAR or sunlight is supplemented with UV radiation, which reportedly results in partial suppression of leaf peroxidase activities (Fini et al., 2011).

\section{Acknowledgement}

Cooperation between participating laboratories was supported by the Hungarian Scientific Grant Agency (grant number OTKA NN85349).

\section{Contributions}

ÉH and PJD conceived the original idea, while the experimental work was carried out by PM, GyCz and GyS, and coordinated by ÉH. The manuscript was for the most part written by ÉH, PJD and PM with contributions from all co-authors. ÉH and $\mathrm{GyCz}$ designed Fig. 1.

\section{References}

Agati, G., Tattini, M., 2010. Multiple functional roles of flavonoids in photoprotection. New. Phytol. 186, 786-793.

Allen, D.J., McKee, I.F., Farage, P.K., Baker, N.R., 1997. Analysis of limitations to $\mathrm{CO}_{2}$ assimilation on exposure of leaves of two Brassica napus cultivars to UV-B. Plant Cell Environ. 20, 633-640.

Apel, K., Hirt, H., 2004. Reactive oxygen species: metabolism, oxidative stress, and signal transduction. Annu. Rev. Plant Biol. 55, 373-399.

Ballaré, C.L., Caldwell, M.M., Flint, S.D., Robinson, S.A., Bornman, J.F., 2011. Effects of solar ultraviolet radiation on terrestrial ecosystems. Patterns, mechanisms, and interactions with climate change. Photochem. Photobiol. Sci. 10, 226-241.

Barta, Cs, Kálai, T., Hideg, K., Vass, I., Hideg, É., 2004. Differences in the ROS generating efficacy of various ultraviolet wavelengths in detached spinach leaves. Funct. Plant Biol. 31, 23-28.

Bassman, J.H., Robberecht, R., Edwards, G.E., 2001. Effects of enhanced UV-B radiation on growth and gas exchange in populus deltoides Bartr ex Marsh. Int. J Plant Sci. 162, 103-110.

Benzie, I.F.F., Strain, J.J., 1996. The ferric reducing ability of plasma (FRAP) as a measure of "antioxidant power": the FRAP assay. Anal. Biochem. 239, 70-76.

Bradford, M.M., 1976. A rapid and sensitive method for the quantitation of microgram quantities of protein utilizing the principle of protein-dye binding. Anal. Biochem. 72, 248-254.

Brosché, M., Strid, Å., 2003. Molecular events following perception of ultraviolet-B radiation by plants: UV-B induced signal transduction pathways and changes in gene expression. Physiol. Plant 117, 1-10.

Caldwell, M.M., Robberecht, R., Flint, S.D., 1983. Internal filters: prospects for UVacclimation in higher plants. Phys. Plant 58 (3), 444-450.

Carletti, P., Masi, A., Wonisch, A., Grill, D., Tausz, M., Ferretti, M., 2003. Changes in antioxidant and pigment pool dimensions in UV-B irradiated maize seedlings. Environ. Exp. Bot. 50, 149-157.

Childs, R.E., Bardsley, W.G., 1975. The steady-state kinetics of peroxidase with 2,2'azino-di-(3-ethyl-benzthiazoline-6-sulphonic acid) as chromogen. Biochem. J. 145, 93-103.

Czégény, Gy, Wu, M., Dér, A., Eriksson, L.A. Strid, Å., Hideg, É., 2014. Hydrogen peroxide contributes to the ultraviolet-B $(280-315 \mathrm{~nm})$ induced oxidative stress of plant leaves through multiple pathways. FEBS Lett. 588, 2255-2261.

Fini, A., Brunetti, C., Di Ferdinando, M., Ferrini, F., Tattini, M., 2011. Stress-induced flavonoid biosynthesis and the antioxidant machinery of plants. Plant Signal. Behav. 6, 709-711.

Flint, S.D., Caldwell, M.M., 2003. A biological spectral weighting function for ozone depletion research with higher plants. Physiol. Plant 117, 137-144.

Garcia Macias, P., Ordidge, M., Vysini, E., Waroonphan, S., Battey, N.H., Gordon, M.H. Hadley, P., John, P., Lovegrove, J.A., Wagstaffe, A., 2007. Changes in the flavonoid and phenolic acid contents and antioxidant activity of red leaf lettuce (Lollo Rosso) due to cultivation under plastic films varying in ultraviolet transparency. J. Agr. Food Chem. 55 (25), 10168-10172.

Genty, B., Briantais, J.-M., Baker, N.R., 1989. The relationship between the quantum yield of photosynthetic electron transport and quenching of chlorophyll fluorescence. Biochim. Biophys. Acta 990, 87-92.

Giannopolitis, C.N., Ries, S.K., 1977. Superoxide dismutase. I. Occurrence in higher plants. Plant Physiol. 59, 309-314.

Havir, E.A., McHale, N.A., 1987. Biochemical and developmental characterization of multiple forms of catalase in tobacco leaves. Plant Physiol. 84, 450-455.

Hideg, É., Jansen, M.A.K., Strid, Å., 2013. UV-B exposure, ROS and stress: inseparable companions or loosely linked associates? Trends Plant Sci. 18, 107-115.

Hideg, É., Vass, I., 1996. UV-B induced free radical production in plant leaves and isolated thylakoid membranes. Plant Sci. 115, 251-260.

Jenkins, G.I., 2009. Signal transduction in responses to UV-B Radiation. Annu. Rev. Plant Biol. 60, 407-431.

Kliebenstein, D.J., Monde, R., Last, R.L., 1998. Superoxide dismutase in Arabidopsis: an eclectic enzyme family with disparate regulation and protein localization. Plant Physiol. 118, 637-650.

Liu, L., Gitz, D.Z., McClure, J.W., 1995. Effects of UV-B on flavonoids, ferulic acid, growth and photosynthesis in barley primary leaves. Physiol. Plant 93, 725-733. 
Majer, P., Hideg, É., 2012a. Developmental stage is an important factor that determines the antioxidant responses of young and old grapevine leaves under UV irradiation in a green-house. Plant Physiol. Biochem. 50, 15-23.

Majer, P., Hideg, É., 2012b. Existing antioxidant levels are more important in acclimation to supplemental UV-B irradiation than inducible ones: studies with high light pretreated tobacco leaves. Emir. J. Food Agric. 24, 598-606.

Majer, P., Neugart, S., Krumbein, A. Schreiner, M., Hideg, É, 2014. Singlet oxygen scavenging by leaf flavonoids contributes to sunlight acclimation in Tilia platyphyllos. Environ. Exp. Bot. 100, 1-9.

Majer, P., Stoyanova, S., Hideg, É., 2010. Do leaf total antioxidant capacities (TAC) reflect specific antioxidant potentials? - a comparison of TAC and reactive oxygen scavenging in tobacco leaf extracts. J. Photochem. Photobiol. B 100, $38-43$.

Middleton, E.M., Teramura, A.H., 1993. The role of flavonol glycosides and carotenoids in protecting soybean from ultraviolet-B damage. Plant Physiol. 103 (3), $741-752$.

Mittler, R., Zilinskas, B.A., 1993. Detection of peroxidase activity in native gels by inhibition of ascorbate-dependent reduction of nitroblue tetrazolium. Anal. Biochem. 212, 540-546.

Neill, S.J., Desikan, R., Clarke, A., Hurst, R.D., Hancock, J.T., 2002. Hydrogen peroxide and nitric oxide as signalling molecules in plants. J. Exp. Bot. 53, 1237-1247.

Nogues, S., Allen, D.J., Morison, J.I.L., Baker, N.R., 1999. Characterization of stomatal closure caused by ultraviolet-B radiation. Plant Physiol. 121, 489-496.
Sabater, B., Martín, M., 2013. Hypothesis: increase of the ratio singlet oxygen plus superoxide radical to hydrogen peroxide changes stress defense response to programmed leaf death. Front. Plant. Sci. 4, 479.

Schneider, C.A., Rasband, W.S., Eliceiri, K.W., 2012. NIH Image to ImageJ: 25 years of image analysis. Nat. Methods 9, 671-675.

Song, N.H., Yin, X.L., Chen, G.F., Yang, H., 2007. Biological responses of wheat (Triticum aestivum) plants to the herbicide chlorotoluron in soils. Chemosphere 68, $1779-1787$.

Stoyanova, S., Geuns, J., Hideg, É., Van den Ende, W., 2011. The food additives inulin and stevioside counteract oxidative stress. Int. J. Food Sci. Nutr. 62, 207-214.

Strid, Å., Chow, W.S., Anderson, J.M., 1990. Effects of supplementary ultraviolet-B radiation on photosynthesis in Pisum sativum. Biochim. Biophys. Acta 1020, 260-268.

Van Camp, W., Inzé, D., Van Montagu, M., 1997. The regulation and function of tobacco superoxide dismutases. Free Radic. Biol. Med. 23, 515-520.

Yannarelli, G.G., Gallego, S.M., Tomaro, M.L., 2006. Effect of UV-B radiation on the activity and isoforms of enzymes with peroxidase activity in sunflower cotyledons. Environ. Exp. Bot. 56, 174-181.

Yang, C.M., Chang, K.W., Yin, M.H., Huang, H.M., 1998. Methods for the determination of the chlorophylls and their derivatives. Taiwania 43, 116-122.

Zhang, W.J., Björn, L.O., 2009. The effect of ultraviolet radiation on the accumulation of medicinal compounds in plants. Fitoterapia 80, 207-218. 